\title{
Honey clinically stimulates granulation and epithelialization in chronic wounds: a report of two cases
}

\author{
Putu E.P. Kefani, Ida B.A.D. Putra, Ratna R.N. Roosseno
}

Department of Plastic and Reconstructive Surgery, Mangusada Hospital, Bali, Indonesia

\section{ABSTRACT}

Various studies have been widely reintroduced honey as a wound dressing in chronic wound treatment. However, its utilization in Indonesia is still very limited. This study reported the effect of honey in stimulating the epithelialization and granulation on chronic wound treatment in our center. Two chronic wound cases, diabetic foot ulcer patient and gangrenous extravasation due to sodium bicarbonate, were daily treated with honey applications. After six-week evaluation, clinically the tissue granulation and epithelization were seen at the edge of the observed wounds and decreased the wound size significantly with no reported side effects. Honey clinically stimulates the epithelialization and granulation on chronic wound treatment.

Keywords: chronic wounds, epithelialization, granulation, honey pISSN: 0853-1773• eISSN: 2252-8083・https://doi.org/10.13181/mji.v27i1.1457• Med J Indones. 2018;27:62-8

- Received 29 May 2016 • Accepted 24 Jan 2018

Corresponding author: Putu E.P. Kefani

dr.kefani@gmail.com

Copyright @ 2018 Authors. This is an open access article distributed under the terms of the Creative Commons Attribution-NonCommercial 4.0 International License (http://creativecommons.org/licenses/by-nc/4.0/), which permits unrestricted non-commercial use, distribution, and reproduction in any medium, provided the original author and source are properly cited. 
Chronic wounds are the wounds that last for more than two weeks without passing through the healing phases perfectly, or usually called recurrent wound. ${ }^{1-3}$ Chronic wounds represent significant burden to patients and health care professionals. In the United States (US) health care system, chronic wound affects 5.7 million patients and costs an estimated 20 billion dollars annually. ${ }^{1}$ There is no epidemiological data of chronic wounds in Indonesia, but it is clear that wherever the site of chronic wounds occur, it increases the morbidity and lowers the quality of life of the patients.

To effectively manage chronic wound problems, understanding understand the normal healing process, factors that influence the healing process, and the emerging concepts in chronic wound management. the understand of normal healing process and factors that influence the healing process, and the emerging concepts in chronic wound management are crucial. ${ }^{1,2}$ (1) Debridement and necrotomy must be done regularly to eliminate the inhibiting factors in wound healing, ${ }^{1,2}(2)$ the nutrition and treatment of the underlying disease must always be evaluated to ensure that the patients have good nutrition to accelerate the wound healing, ${ }^{1,2,4}$ and (3) the principles of moist bed should also be done by selecting the appropriate wound dressing. ${ }^{1,2,5}$

Further study is needed to find the most ideal form of wound dressing, taking into account of various aspects such as quality, effectiveness, and price. Honey is one of the traditional substance that has been used for thousands of years as a wound dressing, but its use has been abandoned by the presence of modern treatment..$^{5-7}$

Nowdays, many studies have been widely reintroduced honey as a wound dressing. ${ }^{5-15}$ In Jakarta (Cipto Mangunkusumo Hospital, Indonesia), histology and pharmacology studies show that local honey has the ability to stimulate chronic wound healing process in patients with diverse causes. ${ }^{7}$ However, the utilization of honey as wound dressing in Indonesia is very limited as current studies are only centralized in Jakarta. In Bali, most centers usually use modern (albeit is expensive) or conventional wound dressing such as topical antibiotic and moist saline wound dressing, Meanwhile honey is a substance that easily obtains and is relatively more affordable compared with other wound dressings in all around Indonesia.
In this study, we clinically evaluated the healing process of two unique chronic wound cases in our center (in Bali) that were treated by using honey alone as the wound dressing. The first case was wagner grade III diabetic foot ulcers pedis sinistra (post refreshing wound) which was previously unresponsive to surgery debridement and conventional wound treatment for almost three months. The second case was uncommon grade III gangrenous extravasation of sodium bicarbonate on antebrachii sinistra (post necrotomy + exploration of multiple abscesses + refreshing wound). Honey used in this study was pure honey taken from the nectar of kapok flowers (Nusantara ${ }^{\circledR}$, Jakarta, Indonesia). Wound dressings used were sterile gauze that had been smeared with honey. Wound care was performed every day and evaluated every 2 weeks to assess the signs of infection and the healing process of these wounds.

\section{CASE 1}

Patient female, 24 years old, with Wagner grade III diabetic foot ulcer, has been through a debridement surgery and previous conventional wound care for approximately 3 months, but no significant improvements were seen. Before the honey treatment, tissue discontinuity with muscle bed at the left plantar, irregular edges, and swelling around the wound were observed. No active bleeding or exudate seepage were seen. Pus and odor were easily detected. The wound size was $9 \mathrm{~cm} \times 5 \mathrm{~cm} \times 2.5 \mathrm{~cm}$ on the plantar and 4 $\mathrm{cm} \times 3 \mathrm{~cm} \times 1.5 \mathrm{~cm}$ on the medial part of the foot. There were tenderness and nociceptive sensation on the injured area (Figure 1).

The patient then underwent a refreshing wound surgery and minimal flap with no postoperative complications. The patient was discharged from the hospital the day after the surgery with cefixime antibiotic therapy, metronidazole, and mefenamic acid orally for 5 days. The wounds were treated with honey every day. The education was given to maintain the blood sugar levels and the hygiene of the wound.

After two weeks of honey treatment, wound size was decreased to $6.5 \mathrm{~cm} \mathrm{x} 3.6 \mathrm{~cm} \mathrm{x}$ $2.1 \mathrm{~cm}$. her plantar with muscle base, irregular 


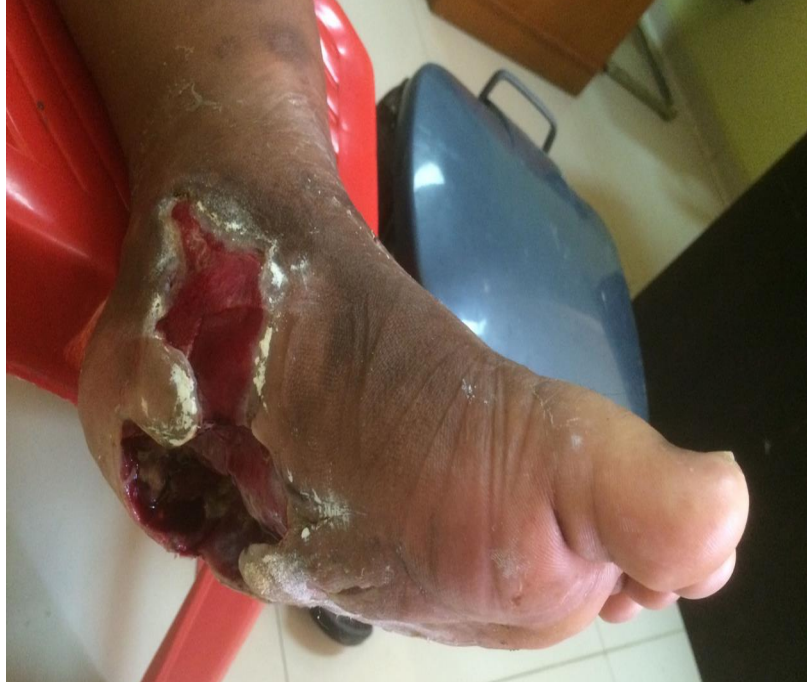

Figure 1. Wagner grade III diabetic foot ulcer before treatment, plantar part size was $9 \mathrm{~cm} \times 5 \mathrm{~cm} \times 2.5 \mathrm{~cm}$, and the medial part size was $4 \mathrm{~cm} \times 3 \mathrm{~cm} \times 1.5 \mathrm{~cm}$

edges, rising granulation tissue covering the muscle, and minimal epithelialization at the wound edges. Edema, active bleeding, pus, and savory odor were no longer found. There was a seepage of translucent yellowish exudate. There were minimal tenderness and nociceptive sensation on the wound (Figure 2A). While in the medial part of the foot, flap was well maintained with granulation tissue on the wound bed, and epithelialization was $0.5 \mathrm{~cm}$ from the wound edge. Neither edema, active bleeding, pus, nor odor were found. There was a seepage of translucent yellowish exudate. Wound size was also decreased to $3 \mathrm{~cm} \times 2 \mathrm{~cm}$ with a minimal tenderness and nociceptive sensation in the wound (Figure 2 B).

After 4-week evaluation, wound on the foot plantar were decreased into size $4.5 \mathrm{~cm}$ x $2.6 \mathrm{~cm}$ x $1.8 \mathrm{~cm}$ with muscle base, irregular edges, rising granulation on the wound bed, and $1 \mathrm{~cm}$ epithelialization from the wound edge (Figure 2C). While on the medial part of the foot, minimal wound with subcutaneous base, irregular edges, no granulation tissue, and almost completely epithelialized were seen. In both of the wounds neither edema, active bleeding, pus, nor odor were found. There was a seepage of translucent yellowish exudate. There was no tenderness, and patient could feel nociceptive sensation on the wound area (Figure 2D).

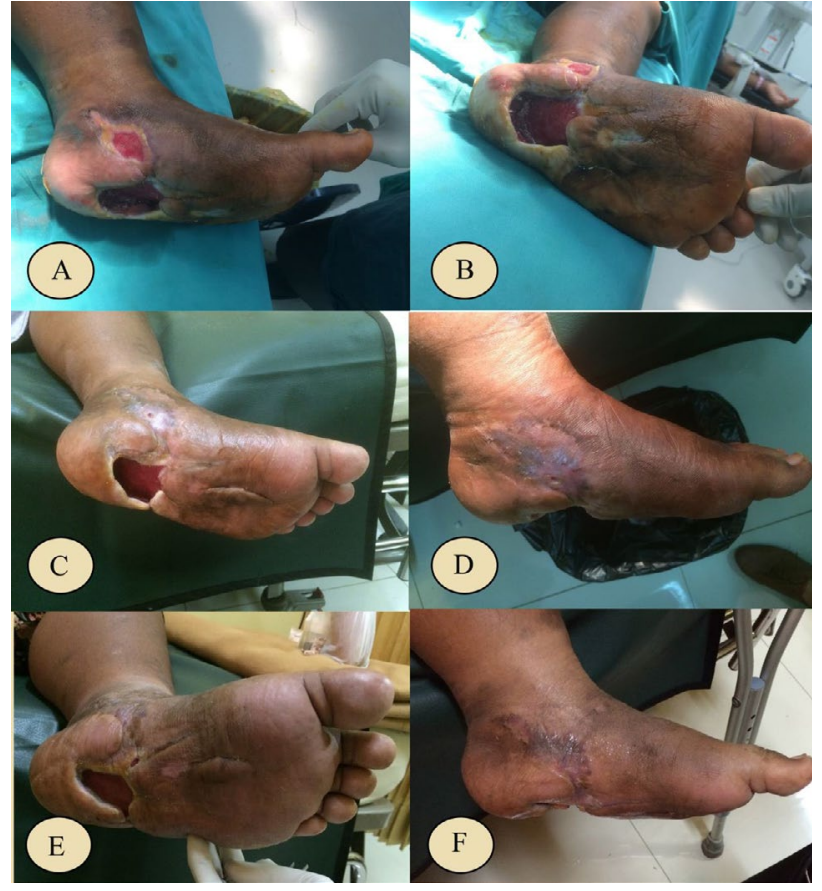

Figure 2. Six-week evaluation after the surgery, patient underwent the honey treatment. (A) Foot ulcer after 2 weeks of treatment, neither pus nor odor were found. Plantar wound size was $6,5 \mathrm{~cm} \times 3,6 \mathrm{~cm} \times 2,1 \mathrm{~cm}$. There were a rising granulation at the base of the wound and minimal epithelialization at the edges of the wound. (B) Foot ulcer after 2 weeks of treatment, medial wound size was $3 \mathrm{~cm} \times 2 \mathrm{~cm}$, and granulation was found at the base of the wound with $0.5 \mathrm{~cm}$ epithelialization from the edges of the wound. (C) After 4 weeks of treatment, on the plantar part, the wound size was 4,5 $\mathrm{cm} \times 2,6 \mathrm{~cm} \times 1.8 \mathrm{~cm}$, muscle tissue was at the base of the wound with rising granulation, there was $1 \mathrm{~cm}$ epithelialization from the wound edges. (D) After 4 weeks of treatment, on the medial part, the granulation tissue was not visible, epithelialization covered almost all parts of the wound. (E) After 6 weeks of treatment, on the plantar part, the wound size was $3.5 \mathrm{~cm} \times 1.8 \mathrm{~cm} \times 1.0 \mathrm{~cm}$, muscle tissue was at the base of the wound with rising granulation, $1.5 \mathrm{~cm}$ epithelialization from the edge of the wound. (F) After 6 weeks of treatment, on the medial part, epithelialization covered the entire wound

After 6-week treatment, on the plantar foot, tissue discontinuities were still visible with on plantar side, wound size was decreased to $3.5 \mathrm{~cm} \mathrm{x} 1.8 \mathrm{~cm} \mathrm{x} 1 \mathrm{~cm}$ muscle base, irregular edges, rising granulation, and epithelialization increased to $1.5 \mathrm{~cm}$ from the wound edge (Figure 2E). While on the medial part, epithelialization has covered the entire wound. Both of these wounds had neither edema, active bleeding, pus, nor odor. There was a seepage of translucent yellowish exudate. With no tenderness, and patient could feel nociceptive sensation in the wound area (Figure 2F). 


\section{CASE 2}

Patient female, 58 years old, with diagnosis of grade III gangrenous extravasation of sodium bicarbonate on antebrachii sinistra. Patient had a history of hemodialysis two months ago. Patient had underwent previous conventional wound care for approximately two months, but no significant improvement was seen. On left antebrachii region, eschar with irregular edges, tissue edema, pus and bad odor were observed. Neither active bleeding nor exudates were found on the wound. Wound size was $24 \mathrm{~cm} \times 6.5 \mathrm{~cm}$. There was tenderness in the wound (Figure $3 \mathrm{~A}$ ).

Patients then underwent necrotomy + exploratory multiple abscesses + wounds refreshing surgery. There were no postoperative complications. Figure 3B shows the condition of the wound the day after surgery. On left antebrachii region, tissue discontinuity with muscles and tendons base and irregular edges were seen. The wound size was unchanged, but there was a seepage of translucent yellowish exudate. Neither tissue edema, active bleeding, pus, nor odor were found. There were minimal tenderness and nociceptive sensation in the wound. The patient was discharged from the hospital the day after the surgery with oral cefixime therapy for 5 days. Wounds were treated with honey every day, and patient education was given to meet the nutritional needs and to maintain the wound hygiene.

After 2-week treatment, patient had no complaint. On the left antebrachii, tissue discontinuity was found with muscles and tendons base, irregular edges, granulation tissue on the wound base, and minimal epithelialization at the wound edges. There was a seepage of translucent yellowish exudate. Neither tissue edema, active bleeding, pus nor odor were found. Wound size decreased to $23.4 \mathrm{~cm} \mathrm{x} 5.9 \mathrm{~cm}$. There were minimal tenderness and nociceptive sensation on the wound area (Figure 4A).

After 4-week evaluation (Figure 4B), patient had no complaint. On the left antebrachii, tissue discontinuity with the subcutaneous tissue base and irregular edges were seen. There were a growing number of granulation tissue and 0.9

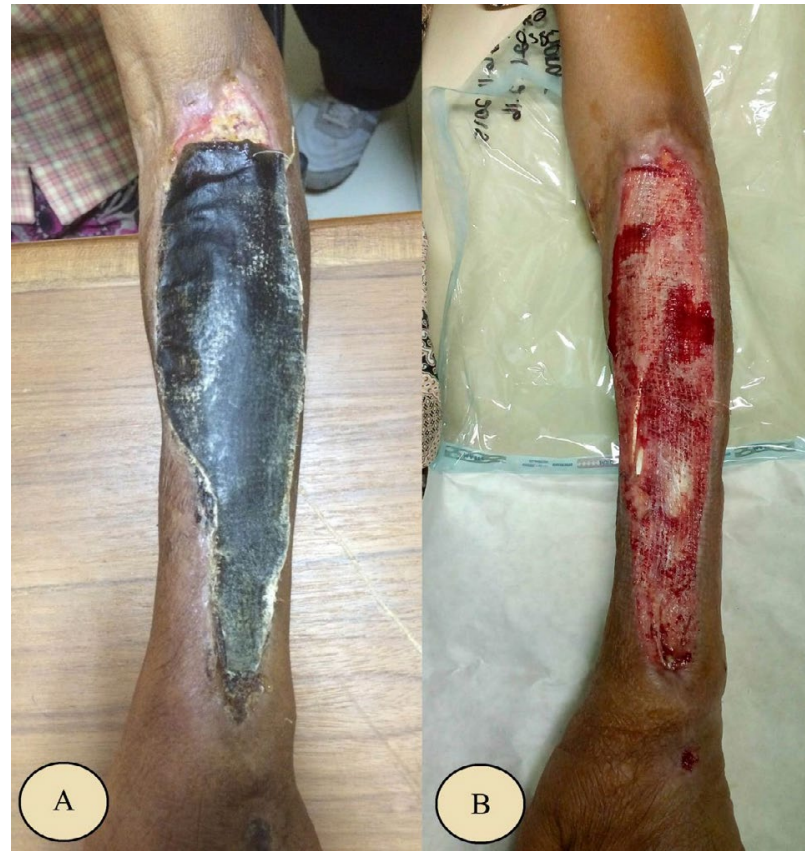

Figure 3. Gangrene on the antebrachii + spacious antebrachii defect + multiple abscesses on the antebrachii sinistra ec. extravasation of sodium bicarbonate prior to treatment. (A) Before the surgery, eschar covered the wound; (B) After the surgery, the wound size was $24 \mathrm{~cm} \times 6.5 \mathrm{~cm}$. Muscle tissue and tendon were at the base of the wound

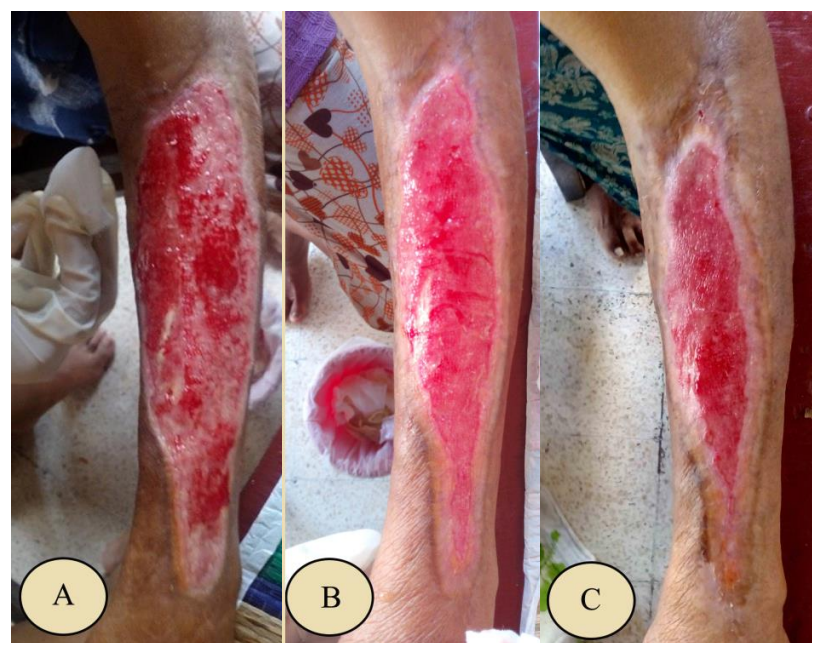

Figure 4. Six-week evaluation of honey treatment. (A) After 2 weeks, muscles and tendons were at the base of the wound, there was granulation at the base and minimal epithelialization at the edge of the wound. Wound size was $23.4 \mathrm{~cm} \mathrm{x}$ $5.9 \mathrm{~cm}$; (B) After 4 weeks, the wound base was subcutaneous with granulation covered the wound, and $0.9 \mathrm{~cm}$ epithelialization was seen from the edge of the wound. Wound size was $22.2 \mathrm{~cm} \times 5.1 \mathrm{~cm}$; (C) After 6 weeks, the wound base was subcutaneous, with granulation covered the wound, and there was $1.5 \mathrm{~cm}$ epithelialization from the wound edges. Wound size was $21 \mathrm{~cm} \mathrm{x} 4.2 \mathrm{~cm}$ 
$\mathrm{cm}$ epithelialization from the wound edges. There was a seepage of translucent yellowish exudate. Neither tissue edema, active bleeding, pus, nor odor were found. Wounds size was decreased to $22.2 \mathrm{~cm} \times 5.1 \mathrm{~cm}$. There was no tenderness on the wound, but patient could feel nociceptive sensation on the wound area.

After 6 weeks of treatment (Figure 4C), patient had no complaint. On the left antebrachii, tissue discontinuity with subcutaneous base and irregular edges were seen. Granulation tissue were covering the wound base, and $1.5 \mathrm{~cm}$ of epithelialization were seen from the wound edge. There was a seepage of translucent yellowish exudate. Neither tissue edema, active bleeding, pus, nor odor were found. Wound size decreased to $21 \mathrm{~cm} \times 4.2 \mathrm{~cm}$ with no tenderness in the wound, but patient could feel nociceptive sensation on the wound area.

\section{DISCUSSION}

There are three principals of chronic wound management which are; (1) debridement and necrotomy, (2) the nutrition and treatment of the underlying disease, and (3) the appropriate wound dressing. ${ }^{1,2,4,5}$ At the beginning, both patients had undergone surgical debridement and necrotomy. There was no problem with nutritional intake. The underlying disease had been optimally treated, and wound treatment was done by using conventional wound dressing that was generally used in Bali (antibiotic powder, tulle, and moist saline wound dressing). Nevertheless, no significant improvement of wound healing was seen on these cases. Patients then underwent re-debridement and necrotomy surgery, and the wound treatment after these re-surgeries were changed to honey-only as the wound dressing. After six-weeks evaluation, without any intervention of nutrition and underlying disease therapy, the wound were slowly getting healed, only by using honey as the wound dressing. This finding supported various studies have been indicated that honey has many advantages in stimulating wound healing when used as a wound dressing in wound care.

\section{Debridement and anti-inflammatory effect}

Many studies have shown that honey has debridement effect which chemically accelerates the wound healing process. It also has an antiinflammatory effect which reduce edema and exudate, provide a calming effect, and minimize the formation of scar..$^{5-9,11-13}$ It is suspected that the anti-oxidant components of honey such as flavonoids, monophenolics, polyphenols, and vitamin $\mathrm{C}$, high osmotic pressure in honey, as well as the hydrogen peroxide composition are related to these findings. ${ }^{5,79-14}$ High osmolarity can draw the water from the wound base and creating an outflow from the lymph, thus reducing tissues edema around the wound. 5,7,10,11 Hydrogen peroxide stimulates the activity of the protease and improves plasmin activity in digesting fibrin on the surface of the wound. . $^{5,14,15}$ In our cases, initial evaluations in the first case indicates a fairly extensive tissue discontinuities, especially on the plantar and medial part of the left foot. Swelling was seen around the wound, but neither active bleeding nor seepage of exudate were found. While in the second case, the left antebrachii region also showed a fairly extensive tissue discontinuity without tissue swelling. There was a seepage of translucent yellowish exudate and no active bleeding. After the treatment with honey wound dressing in both cases, the signs of inflammation began to decrease. There was no tissues swelling around the wound, there was a seepage of translucent yellowish exudate, and there was no active bleeding. This is consistent with the theory that honey has a debridement and anti-inflammatory effect.

\section{Stimulate the tissue growth}

Honey effect in stimulating the growth of tissue granulation and epithelization in these cases were observed during therapy. Both defects had contracted signifcantly. The granulation tissue was progressively rising, and the epithelialization was widening at the edges of the wound. The difference in the progression of wound healing in both of these cases might be caused by the patient's general condition and the age. The first patient was 24 years old and has diabetes mellitus with uncontrolled blood sugar, while the second patient was 58 years old. and has a low body weight and tends to be malnourished. It is known that some of the factors responsible for the wound-healing process, among other things are the existence of systemic problems such as diabetes mellitus and malnutrition. Both of these decreased the immune function of patients. ${ }^{1,2,4}$ 
The wound healing process in both cases was still running progressively. The ability of honey to stimulate granulation and epithelialization in the treatment of chronic wounds was caused by the nutrient compositions such as carbohydrates, amino acids, vitamins and minerals that were easily metabolized. This evident from many studies have shown that wounds will heal faster if they are provided with a mixture of nutrients. Honey provides glucose for epithelial cells, leukocytes, and glycolysis. In the process of epithelialization, cells need carbohydrate to migrate to the surface of the wound, so that it can perform wound closure. ${ }^{13}$ In addition, honey also has a high acidity level as to maximize the process of wound healing by increasing the release of oxygen from hemoglobin and to minimize the damage caused by the activity of matrix proteases. On the principle of the wound management, it is generally known that oxygen is required for metabolism and synthesis of collagen tissue. $^{2}$

\section{The antibacterial activity}

In these cases, the sign of infection such as pus and bad odor were not found after using honey dressings. It can be related to the antibacterial activity of honey which has been reported in previous studies. ${ }^{5-11}$ Many studies have shown the healing property of honey is due to its antibacterial activity, ability to maintain a moist wound condition, and high viscosity helps to provide a protective barrier to prevent infection. Its immunomodulatory property is also relevant to wound repair. The antimicrobial activity in most of honey is due to the enzymatic production of hydrogen peroxide. However, another kind of honey, called non-peroxide honey (such as manuka honey), displays significant antibacterial effects even when the hydrogen peroxide activity is blocked. This mechanism may be related to the low $\mathrm{pH}$ level of honey and high sugar content (high osmolarity) that is enough to hinder the microbial growth. The medical grade honeys have potent in vitro bactericidal activity against antibiotic-resistant bacteria causing several lifethreatening infections to humans. However, there is a large variation in the antimicrobial activity of some natural honeys due to spatial and temporal variation in sources of nectar. ${ }^{5,6,9-11}$

In Indonesia, currently foreign honey can only be found in a big city which is more expensive than the local one (Indonesia honey). There was one study has explored the efficacy of local honey. The study compared the effectiveness of foreign honey with local honey in their antibacterial activity using three types of bacteria that are notoriously dangerous and difficult to eradicate, such as Pseudomonas sp., Staphylococcus sp., and Methicillin-resistant Staphylococcus aureus (MRSA). It local honey has similar ability to inhibit the growth of bacteria especially with high level of purity (100\%). The physical-chemical properties of local Indonesia honey and foreign honey are not much different, so that Indonesia honey can also be used for infected wound treatment. ${ }^{7}$

In these cases, honey has the ability to stimulate granulations and epithelializations in chronic wound treatment with no reported side effects. State honey could be considered as an ideal form of alternative modality in chronic wound treatment. Moreover, honey is easily obtained and relatively cheap in Indonesia. Further experimental studies are needed to assess the effectiveness of Indonesian honey in chronic wound treatment, included to compared to other modalities that have been used in Indonesia.

\section{Conflict of interest}

The authors affirm no conflict of interest in this study.

\section{REFERENCES}

1. Torre, JI. Medscape [Internet]. Chronic Wound. [cited 2015 Dec 11]. Available from: http://emedicine. medscape.com/article/1298452-overview\#showall.

2. Diegelmann RF, Evans MC. Wound Healing: an overview of acute, fibrotic and delayed healing. Front in Biosci. 2004;9:283-9.

3. Gurtner GC. Wound Healing: Normal and Abnormal. In: Grabbdan S., editor. Plastic Surgery 6 th Edition. Philadelphia: Lippincott. 2007; 15-22.

4. MacKay D, Miller AL. Nutritional Support for wound healing. Altern Med Rev. 2003; 8(4):359-77.

5. Molan P, Rhodes T. Honey: A biologic wound dressing. Wounds. 2015;27(6):141-51.

6. Molan PC. Re-introducing honey in the management of wounds and ulcers - theory and practice. Ostomy Wound Manage. 2002;48(11):28-40.

7. Sudjatmiko G. Madu untuk obat luka kronis. Jakarta: Yayasan Khasanah Kebajikan. 2011; 7-31. Indonesian.

8. Ingle R, Levin J, Polinder K. Wound healing with honey - a randomized controlled trial. S Afr Med J. 2006;96(9):831-5.

9. Zbuchea A. Up-to-date use of honey for burns treatment. Ann Burns Fire Disasters. 2014;27(2):22-30. 
10. Mandal MD, Mandal S. Honey: Its medicinal property and antibacterial activity. Asian Pac J Trop Biomed. 2011;1(2):154-60.

11. Yaghoobi R, Kazerouni A, Kazerouni O. Evidence for clinical use of honey in wound healing as an antibacterial, anti-inflammatory anti-oxidant and antiviral agent: a review. Jundishapur J Nat Pharm Prod. 2013;8(3):100-4.

12. Zhao G, Usui ML, Lippman SI, James GA, Stewart PS, Fleckman $\mathrm{P}$, et al. Biofilms and inflammation in chronic wounds. Adv Wound Care (New Rochelle). 2013;2(7):389-99.

13. Henriques A, Jackson S, Cooper R, Burton N. Free radical production and quenching in honeys with wound healing potential. J Antimicrobial Chemother. 2006;58(4):773-7.

14. Molan PC. Debridement of wounds with honey. J Wound Technol. 2009;5:12-17.

15. Witman CE, Downs BW. Topical honey for scalp defects: an alternative to surgical scalp reconstruction. Plast Reconstr Surg Glob Open. 2015;3(5):e393. 